\title{
Awareness among general public of India towards COVID-19 pandemic: A questionnaire-based cross- sectional study
}

Vikas Maharshi ( $\square$ vikas.maharshi81@gmail.com )

All India Institute of Medical Sciences New Delhi https://orcid.org/0000-0003-0218-3325

Puja Puja

Jawaharlal Nehru Medical College and Hospital

Dheeraj Kumar Jakhar

PGIMS, Rohtak

Vishwajeet Singh

All India Institute of Medical Sciences New Delhi

Research article

Keywords: Coronavirus disease 2019, COVID-19, SARS-CoV-2, pandemic, knowledge, attitude, practice.

Posted Date: July 28th, 2020

DOI: https://doi.org/10.21203/rs.3.rs-42220/v1

License: (c) (i) This work is licensed under a Creative Commons Attribution 4.0 International License.

Read Full License 


\section{Abstract}

Background: Control of a pandemic is influenced considerably by practices followed by the general public which in turn is supposed to be influenced by the knowledge and its attitude. The study intended to assess the knowledge, attitude, and practices (KAP) among the general public of India towards transmission of COVID-19.

Methods: A self-administered questionnaire was prepared from the awareness material available on the WHO and Ministry of Health \& Family Welfare, India websites. The questionnaire contained 35 items (scored and un-scored both) in total (' 9 ' from each viz KAP and ' 8 ' to collect demographic details) and was sent to 600 people through e-mail for convenience sampling. The scores for KAP for an individual could range from 0-9, -5 to 5 and 0-8 respectively. Demographic variables were compared for scores attained and an association among KAP was measured.

Results: A total of 229 volunteers representing different states/union territories were included in the analysis. The mean \pm SD scores attained for KAP were 3.9 $\pm 1.9,2.6 \pm 2.1$, and $5.9 \pm 1.9$ respectively. Around $39.7 \%$ of the individuals had adequate knowledge (score $\geq 50 \%$ of the maximum), $82.1 \%$ showed positive attitude (score $>0$ ) and $82.9 \%$ revealed appropriate practices (score $\geq 50 \%$ of the maximum). The scores attained by different age groups and genders were comparable. A fair correlation between KA, KP, and a good correlation between AP was found. The associations of KAP with each other were statistically significant $(p<0.001)$.

Conclusion: A positive attitude and appropriate practices were seen in the majority whereas adequate knowledge was there in a fair number of participants. Overall awareness among the general public of India was satisfactory.

\section{Background}

The Coronavirus outbreak in the year 2019-20 started in Wuhan city, Hubei Province, China [1]. The disease caused by the virus is named as 'Corona Virus Disease 2019 (COVID-19) and the causative strain of the virus is termed as 'Severe Acute Respiratory Syndrome Corona Virus-2 (SARS-CoV-2) by World Health Organization (WHO), which was previously named as a novel or new Coronavirus 2019 (2019$\mathrm{nCoV}$ ) [2].

After its initial outbreak in China, new cases of the disease started emerging in other parts of the World including Japan, Italy, Iran, Spain, South Korea, France, and the United States [3]. COVID-19 was declared as a 'public health emergency of international concern' on 30th January 2020 [4] and as a pandemic on 11 March 2020 by WHO [5]. It is the first pandemic caused by the Coronavirus [5] and the second pandemic of the 21st century after that caused by the influenza A (H1N1)pdm09 virus in the year 2009 [6]. In countries other than China, its spread occurred initially because of the migration of people. As of 29th April 2020 more than 200 countries/areas/territories have been caught by this pandemic with more than 2900-thousand confirmed cases and $>200$-thousand deaths worldwide [7]. 
Given rapidly increasing number of positive cases and seriousness of the situation, the Governments of various countries including that of India, started taking action(s) including preparing and circulating the awareness material like posters in English and other vernacular languages, formulating guidance documents for awareness of the general public, guidance documents for healthcare professionals, formulating comics to create awareness among children and finally locking-down the region(s) completely or partially. Despite these efforts made at the administration level, the cases of COVID-19 are increasing globally (though the rate of rising is relatively lower in India), one of the reasons could be the lack of awareness (could be due to a knowledge gap, false attitude/beliefs, and wrong practices followed) among the population about precautionary measures for prevention of transmission and/or lack of sensitization about the seriousness of the situation. Without making efforts at the personal level by the general public, the steps taken by the administration may not prove to be fully effective. Knowledge and attitude at the personal level may affect the practice followed and thus in turn the spread of the disease in the community. Therefore this study was conducted to know the awareness of the general public in India about COVID-19 in terms of their knowledge, attitude, and practice (KAP).

\section{Methods}

\section{Objectives}

The objective of this questionnaire-based, cross-sectional study was to assess the knowledge, attitude, and practices of the general public of India towards the transmission of SARS-CoV-2 and measures to prevent it.

\section{Outcomes}

1. Knowledge, attitude and practice scores

2. Comparison of knowledge, attitude and practice parameters among various demographic characteristics

3. Association of knowledge, attitude and practice parameters with each other

\section{Eligibility criteria}

Adult (age $\geq 18$ years) citizens of either gender of India who wished to give online consent and to participate in the study were enrolled. The healthcare professionals (doctors including dentists, nursing staff, and pharmacists) and the persons who do not understand the written English language were excluded from the study.

\section{Formulation of the study-tool}

The knowledge, attitude, and practice of the general public of India were assessed through a selfadministered questionnaire. Websites of WHO and Ministry of Health \& Family Welfare (MoHFW), India, were accessed and the material available for the awareness of the general public was downloaded. The 
content was read thoroughly, based on which, a draft questionnaire relevant for the general public was prepared. Content, readability, and ease of filling of the questionnaire were kept in mind while preparing the questions. The draft was circulated to all the members of the research team and modified according

to feedback received. The pre-finalized questionnaire was applied to twenty persons randomly among the general public in a pilot manner to evaluate the validity of the content, readability, ease of filling, and whether or not it conforms to the purpose, it is designed for. Based on the results obtained from the pilot application, the questionnaire was modified and the same were reconfirmed. The final questionnaire [Supplementary material] containing 35 questions or items (QD1-QP9) in total for assessment of KAP (nine questions for each parameter) largely towards the transmission of COVID-19 and/or its causative organism, apart from those on demographic details and current general health, was made in the google form. Instructions related to eligibility, online consent for participation, and responding to the questions were mentioned in the initial part of the google form.

\section{Enrollment of participants}

Concerning the social distancing and regional regulations during the lock-down period in the current situation of COVID-19, the ethical requirement was fulfilled by recruiting the participants through obtaining online consent without approaching them physically. Convenience sampling was used to enroll the participants. The link to access the questionnaire was sent through electronic mail (e-mail) to the general public in various states/union territories of India. Persons were free to decide whether or not to fill the questionnaire. Voluteers providing the consent were able to give their responses by filling the questionnaire. Provision of personal information was optional in the questionnaire. However, all the responses received were kept confidential without revealing them to the third party. Duplications of responses were prevented by allowing each volunteer to submit the response once only. The questionnaire was open to receive the responses between $25^{\text {th }}$ March 2020 and $18^{\text {th }}$ April 2020, a period during the complete lock-down in the country.

\section{Statistical analysis}

All the responses were saved as individually filled google forms as well as in the Microsoft Excel sheet. Descriptive analysis was used to describe the demographic characteristics and individual responses. All the categorical variables were presented as numbers and percentages while the continuous variables were expressed as mean (standard deviation) and/or median (inter-quartile range) according to the distribution of the data. To find out the association between categorical independent variables, Chisquare test/ Fishers' exact test was used. To compare the quantitative variables (scores) between the two groups, the Students' t-test/ Wilcoxon rank-sum test was used and for more than two groups, the ANOVA was used. Pearson's correlation or Spearman's rank correlation coefficient was used to evaluating the relationship between the KAP scores. A p-value of $<0.05$ was taken as statistically significant. Statistical software, STATA/SE version 14.2 (StataCorp LP, College Station, TX, USA) was used for the analysis. 


\section{Results}

The questionnaire was sent through e-mail to 600 people living in various states/union territories of India. Two hundred and ninety-two persons agreed to provide online consent and responded to the e-mail. Of these volunteers, 39 were healthcare professionals, 15 were minors (less than 18 years of age) and nine did not mention their age and therefore were excluded from the study. Finally the remaining 229 volunteers were eligible and included in the analysis (Figure 1). Detailed descriptive data are presented in Tables 1, 2, 3, and 4.

\section{Demographic characteristics}

The majority (86.5\%) of the participants aged between 18 and 45 years whereas $4.4 \%$ were elderly. $\mathrm{A}$ male preponderance $(62.5 \%$ were males and rest females) was observed in the study sample.

The maximum numbers of responses received were from the state Rajasthan $(22.7 \%)$ followed by those from Haryana (13.1\%), and Delhi (11.4\%) respectively. Of all the participants, $85.5 \%$ were not suffering and/or did not suffer from flu-like symptoms within the previous 14 days of application of the questionnaire whereas $14.4 \%$ did. None of the participants had been tested positive for COVID-19. The details of demographic data are presented in Table 1.

\section{Assessment of knowledge towards COVID-19}

The responses of the participants to the questions assessing their knowledge towards COVID-19 are described in Table 2. Questions focusing on the mode of transmission, measures to prevent community spread, home care of the suspected case or a patient, and management of dead body of a COVID-19 patient, relevant to the general public, were used to assess the knowledge.

All the questions testing the knowledge parameter were given a scoring (score ' 1 ' for each response indicating the presence of the correct knowledge and ' 0 ' for the incorrect response). Thus the knowledge scores for individuals were calculated as ' 0 ' or ' 1 ' and added up to give a total knowledge score. The score-range for the knowledge portion of the questionnaire was between ' 9 ' and ' 0 ' (the maximum and the minimum possible scores respectively).

Of all the participants, 91 (39.7\%) showed the presence of adequate knowledge about COVID-19 with a score $\geq 50 \%$ of the maximum i.e. score $\geq 5$. Poor knowledge was apparent primarily in the questions $\mathrm{K} 2$ (31.4\%), K3 (32.1\%), K4 (48.9), K5 (30.7\%), K8 (36.2\%), and K9 (29.8\%). The maximum numbers of correct responses were received for the questions K7 (72.4), K6 (69.1), and K1 (58.4) respectively. The mean knowledge score for the entire study cohort was $3.9( \pm 1.9)$. For detailed descriptive data please refer to Table 2.

\section{Assessment of attitude towards COVID-19}


Among the questions testing the attitude parameter, five were related to assessing positivity or negativity in the attitude in context with COVID-19 pandemic and were scored (score ' 1 ' for each response indicating positive attitude which may be helpful to control the transmission, ' -1 ' for those indicating negative attitude which may impart to aggravate the transmission and ' 0 ' for the neutral responses) whereas rest four questions (without scoring) were framed just to know the attitude of the public without the availability of strong evidence in favor or disfavor of the content asked. The score ranged from a maximum of ' 5 ' to a minimum of ' -5 '. The scale classified the attitude as 'positive' with score ' $>0$ ', 'negative' with that ' $<0$ ', and neutral with a score of ' 0 '.

The majority of the respondent i.e. $188(82.1 \%)$ showed overall positivity in their attitude, whereas 16 $(6.99 \%)$ were neutral. Most $(89.4 \%)$ of the respondents think that taking precautions at a personal level will benefit human society to combat the current pandemic. Overall the respondents had a positive attitude towards COVID-19 with a mean $( \pm S D)$ score of $2.6( \pm 2.1)$ and median (IQR) of $3.0(4.0)$. For detailed descriptive data for the attitude parameter, please see Table 3.

\section{Assessment of practices towards COVID-19}

Practices followed by the general public towards COVID-19 were assessed by putting nine questions as shown in Table 4. Among the items assessing the practices followed, eight were scored, of which two were given a graded scoring $(0.25,0.5,0.75$ and 1 for the practices which are the least to the most helpful in the prevention of transmission respectively) whereas the remaining six questions were scored as ' 0 ' (for the practices which increase the transmission and therefore are not recommended) and ' 1 ' (for the practices which are helpful to control the transmission and therefore are promoted/recommended). The last ninth question was unscored and was formulated only to know the extent of a particular practice being followed by the public. The practice score of an individual can range from a maximum of ' 8 ' to a minimum of ' 0 '.

The majority of the respondents i.e. 200 (92.2) keep a physical distance of at least one meter while communicating with others and $167(78 \%)$ greet their colleagues by 'Namaskar'. Further, It was interesting to know that $64.4 \%$ cough or sneeze Into the inner side of their elbow and $61.9 \%$ wash their hands more than five times a day. Among the participants, $82.9 \%$ attained a score of $\geq 50 \%$ of the maximum possible score. The mean score was $5.9 \pm 1.9$, revealing the commonness of good practices among the study participants. For more details please refer to Table 4.

\section{Association of demographic characteristics and KAP Scores}

Among the demographic variables, age and gender were explored and none were found significantly associated with KAP scores. In other words, the KAP scores achieved by the participants among three age groups were comparable and the same is true for those attained among different genders [Table 5].

\section{Correlation among knowledge, attitude, and practice}


The scores pulled off by the participants reveal a fair correlation between their knowledge and the attitude, and between knowledge and practice whereas a good correlation between attitude and practice. Correlations among all the three parameters viz knowledge, attitude, and practice to each other were also statistically significant [Table 6].

\section{Discussion}

Several factors may influence the spread of communicable diseases including COVID-19 in the community. The first case of COVID-19 was reported in the latter part of December in the year 2019 from China [1]. The disease caused by SARS-CoV-2 is mostly milder but its communicability or spreading potential is much higher than that of the virus which led to Middle East Respiratory Syndrome (MERS) in the year 2012 and almost similar to that of one which sourced the outbreak of SARS in the year 2002 [8], which may be attributable to its ability to be spread by asymptomatic or pre-symptomatic carriers as well $[9,10]$. General thermal screening to detect the presence of fever may many-a-times misses out such a case which could be one of the explanations of speedy spread (within around three months from its initiation) of this new illness to trap a large portion of the World and to get the label of a pandemic [5]. Once its human-to-human transmission was confirmed, public health measures were taken by various nations at their administrative level but still community engagement is equally or rather more valuable to control the spread of COVID-19. People throughout a nation may have diverse knowledge, beliefs, and practices that may directly or indirectly affect the community transmission of COVID-19. Therefore, awareness of the general public of a nation towards COVID-19 (especially its transmission) seems worth to be evaluated.

This study found the presence of correct knowledge, positivity in attitude, and the appropriate practices towards the spread and prevention of transmission of COVID-19 in the majority (>50\%) of the participants.

Because of a lack of evidence on this issue towards this novel ailment especially from India, there is a tiny scope to compare our findings with those of others. However, the relevance of each of the KAP questions used and the responses received for them are discussed here.

SARS-CoV-2 has mainly transmitted through respiratory droplets (diameter $<5-10 \mu \mathrm{m}$ ) and touching the contaminated surfaces $[11,12]$. Respiratory droplets are generated by coughing, sneezing, and even talking especially loudly. Though most of the participants knew the mode of spread of COVID-19 (QK1), a considerable proportion thought of its spread not happening by talking closely, by sharing the same bed and eating in the same utensils [Table 2]. The presence of this knowledge may contribute notably to controlling the community spread of the disease.

The Coronavirus has been seen to remain viable on various surfaces for different time durations e.g. on metallic and plastic surfaces for 2-4 days, on the copper surface for 4 hours, and on the cardboard for 24 hours [13]. The surfaces (which had previously come in contact with a SARS-CoV-2 infected person) touched unknowingly by healthy persons within a specified time frame, may lead to contraction of the 
infection by them. Therefore it becomes important to clean such contaminated surfaces effectively. Sodium hypochlorite solution of a strength of $1 \%$ has been recommended for this purpose [14] but this knowledge was lacking in almost two-thirds of the participants in this study (QK2) [Table 2].

Appropriate use of a medical mask may prevent the acquisition of contagion from an infected person(s). But inappropriate use, on the other hand, may rather harm including causing wastage of resources. A medical mask can be applied properly maximum for 6-8 hours or until it becomes damp, whichever is earlier $[15,16]$. Mask is recommended to be used by COVID-19 patients, healthcare workers, or other persons providing them care, and persons who have flu-like symptoms [15]. Keeping in mind the harmful effects caused by the inappropriate use of a mask including discomfort experienced, higher risk of infection to self and others due to its mishandling and because of limited resources, its routine use by the general public (who is not at high risk to acquire the disease) is not recommended $[15,16]$. Moreover, the use of a mask may give a false sense of undue protection and may make the public to overlook more important measures to be followed like frequent handwashing. This knowledge is lacking in more than two-thirds of the participants (QK3) [Table 2]. Moreover almost half of the participants have not read or not been told by some trained person about the appropriate use of a mask (QK4) [Table 2]. Lack of this knowledge may affect the transmission of the disease unfavorably in the direct and/or indirect way (by depleting the resources and making them unavailable for those who are in a real need).

Separation (quarantine or isolation) is required for persons suffering from COVID-19 or for those who have come in close contact with such patients [14]. For QK5, wide variation in the responses was noticed. Around $30 \%$ of the respondents attempted it correctly, the same number of respondents of this question did not know that separation is not only for COVID-19 patients rather it is for their close contacts or suspected cases who might or might not have contracted the infection, as well, $26 \%$ of the respondents did not know that fever, cough, and difficulty in breathing are not exclusive to COVID-19 and $11 \%$ did not know that frequent hand washing is recommended for all and not only for COVID-19 caregivers [Table 2].

This is a common practice to use a tissue paper for coughing or sneezing but mishandled one may become a potential source of the pathogen. For QK6, more than two-thirds of the participants knew the correct use of tissue paper for coughing or sneezing [Table 2]. SARS-CoV-2 can infect all age groups including children [17]. Because of a different level of understanding in small children, it becomes important to explain and make them aware of the seriousness of the disease and precautions to be taken through age-appropriate means like comics, stories, etc. Around $14.5 \%$ of the respondents of this question did not give importance to making the children aware [Table 2]. Surprisingly, $6.4 \%$ of the respondents of the question did not know the vitality of frequent hand washing for the prevention of transmission of COVID-19 [Table 2]. One of the reasons for the lack of this crucial information could be inaccessibility to or a lack of sensitization to the awareness material.

For QK7, around 72\% of the respondents had the correct knowledge of protecting others including close relatives from coming in their contact [Table 2] following their incidental contact with a confirmed case of COVID-19, and it is the first basic step to stop the spread of COVID-19 once one has got the infection. 
While caring for a COVID-19 person at home, the person should be stayed in a separate well-ventilated room preferably with an attached washroom/bathroom to prevent his/her contact with other persons at the home/household. Ventilated room is recommended because continuous airflow keeps the level of viral particles in the surroundings low and thus reduces the risk of disease transmission to the caregiver(s) as well as may hasten the rate of recovery of the patient [14]. One of the options in QK8 was framed to know this knowledge (importance of good ventilation while quarantining/isolation) among the public. But more than half of the respondents of the question lacked this knowledge. Around $2 \%$ of respondents had incorrect knowledge of regularly shaking the bedsheet/linen of the patient given a false sense of cleanliness [Table 2]. Rather this is a harmful practice [14] because it sheds the viruses in the surroundings, and in turn, increases the risk of transmission. Surprisingly around $8 \%$ of the respondents did not understand the actual meaning of quarantine and agreed with the option 'one visitor at a time may be allowed to meet the patient' [Table 2]. Lack of this critical knowledge seems troubling and warrants to take steps at the administrative or at a personal level to spread the correct knowledge about separation and its role in combating the COVID-19.

There was wide variation in the opinion of the public regarding the handling of the dead body of a COVID19 patient (QK9) [Table 2]. The guidelines do not recommend bathing and hugging to the body for obvious reasons. In the Hindu community, the dead body is cremated (burnt to ash). The funeral may be allowed and ash may be collected because in the presence of high temperature during cremation the ash may be considered a sterile remnant and should not pose a risk of transmission of the infection [18].

'Basic Reproduction Number' $\left(R_{0}\right)$ of SARS-CoV-2 is calculated to be around ' 3 ' which means on an average a sick person infects another three persons [8]. Therefore, various places were locked-down partially or completely for the variable duration by the Governments of different countries including that of India, to reduce the movements of people and in turn to control the spread of infection. Besides this, a few additional steps have been taken by the regional Governments to supply the basic requirements to the doorstep of needy during the period of lock-down, to spread the awareness among the general public, and to improve infrastructure for management of the suspected and/or confirmed cases of COVID-19. Moreover, the Government of India has also launched a mobile application named 'Aarogya Setu' that can indicate a person about his/her suspected contact with a case of COVID-19 through artificial intelligence and it can also tell a level risk of acquiring the infection by a person by asking few pieces of information. Around $75 \%$ of all the respondents agreed with the steps taken by the Government to be helpful to control the spread of SARS-CoV-2, 9.7\% of respondents of the question did not agree with it and the rest were neutral to answer QA1 [Table 3].

Social distancing is considered to be one of the best measures for self-protection as well as protecting others against COVID-19 [19]. Keeping a physical distance from a person suffering from COVID-19 may or may not make him/her feel embarrassed/inferior depending on personal psychology. While answering QA2, slightly less than one-third of the participants agreed with 'patient feeling embarrassed' which may show their emotional lability and these persons had a lower level of knowledge with mean maximum 
knowledge score of 1.5 , though half of the participants had a positive attitude agreeing with the option 'not feeling embarrassed' [Table 3].

While home caring for a person suffering from COVID-19, the minimum number of household members (preferably only one) should come in his/her contact to prevent the spread of the infection to other members [14]. Around two-thirds of the respondents agreed with this fact in QA3 but still, around $27 \%$ of them agreed with 'involvement of all the family members for caring for the patient to make him/her feel emotionally better' and had a lower knowledge score with a mean value of 1.2 [Table 3].

Taking precautions at the personal level directly and/or indirectly affects the spread of communicable diseases including COVID-19 for obvious reasons. Almost $90 \%$ of the individuals show their agreement with the fact but few of them did not while answering QA4 [Table 3]. The reason behind this attitude of a minority of respondents is difficult to guess but may be related to the dearth of knowledge (Average knowledge score for these individuals was 1.2).

The innate immunity may play a role in combating a viral infection and reducing the severity of the symptoms [20] but it may not prevent an individual to get an infection at all, and the spread of the virus has been reported from asymptomatic carriers as previously mentioned. While responding to QA5, a few of the respondents showed having a negative attitude of not getting infected due to a strong immunity therefore not requiring precautionary measures. Rest $~ 85 \%$ agreed with the need to take precautions against it [Table 3]. But such a negative (in context with transmission) attitude even in a minority of people may prove to have grave consequences for self as well as for the rest of the society.

Exclusive breastfeeding to a newborn has become a norm because of its benefits not only to the baby but also to mothers. However, few conditions may not allow this practice like HIV infection in mother, breast abscesses, herpes simplex infection, active hepatitis B, etc. [21]. Whether or not a nursing mother suffering from COVID-19 should breastfeed to her newborn has not been answered clearly because of a lack of evidence on its benefits versus risks. However, SARS-CoV-2 has not been detected yet in the breastmilk [22] More than $85 \%$ of the respondents opined not to breastfeed the newborns while answering QA6, of whom 69 (37.1\%) were females [Table 3].

India is a large country with wide diversity even in Indian culture from region-to-region. Many practices in the ancient Indian culture seem to provide self-protection and in turn, diminish the societal spread of communicable diseases. Examples of such practices are greeting through 'Namaskar', using copper utensils abundantly for storing water, not eating before taking a bath (cleanliness), using separate utensils for food, and so on. But on the other hand, a few of them in the culture may seem to aggravate the transmission of such ailments e.g. large spiritual gatherings, 'Angapradakshinam' practiced by Tamil Hindus $[23,24,25]$ and open-defecation. The culture was considered to be protective by around $42 \%$ of the respondents and not by the $29 \%$, the rest of the participants were neutral in this regard in response to QA7 [Table 3]. 
Several infections including those caused by viruses have been acquired by humans from animals either through their prolonged contact or through the food items obtained from them. The same has also been reported for the human infection of SARS-CoV-2. According to a few sources, SARS-CoV-2 spread originally to humans from unhygienic non-vegetarian food practices in China [1]. One of the previous two Coronavirus outbreaks (SARS) had also its epicenter in China [8] which may support this hypothesis but still concluding remarks cannot be made based on available weaker shreds of evidence. More than $45 \%$ of respondents favored this food-habit as a risk factor whereas around $26 \%$ denied this supposition and rest were neutral while responding to QA8 [Table 3].

Most outbreaks of the diseases caused by Corona- and Influenza viruses (SARS, MERS, Swine flu, bird flu, etc.) indicate their affinity towards a colder climate, for this reason, it was conjectured for the current outbreak/pandemic also to be sensitive enough to be checked by the higher environmental temperature during summer [26], but nobody knows what is hidden in the womb of the future. For QA9, around $44 \%$ of the respondents opined the disease to remain prevalent in India for the next 1-3 months, $29 \%$ thought it to be for the next 3-6 months whereas only around $15 \%$ predicted it to last for more than 6 months [Table 3].

Hospitalization is needed for severe cases of COVID-19; asymptomatic close contacts and the cases with milder disease may be managed at home with quarantine [27]. QP1 was framed to know the awareness regarding self-quarantine. Most (around 56\%) of the respondents chose to practice self-quarantine which shows the presence of widespread knowledge among the general public regarding the importance of this fundamental step in combating with this calamity. But still, more than one-fourth of the respondents chose to go to a hospital, $8 \%$ to call a doctor at home and $6 \%$ to inform others about the illness by going to their homes and all these people choosing an inappropriate practice had an average knowledge score of 1.3 [Table 4].

During home-quarantine, a close-contact or a confirmed case of COVID-19 should restrict his/her activities to a separate room without coming in contact with other household members [14]. QP2 was intended to know whether or not the people practice the quarantine correctly. More than half of the participants probably knew practicing quarantine correctly and therefore they chose the option 'they will wear the mask all/most of the time' considering the first option ('restrict their activities to their household and household members-only') as inappropriate. But nearly $44 \%$ of the respondents chose the first option as the right practice [Table 4].

Appropriate hand cleanliness is vital to keep self-protected against SARS-CoV-2 infection. If hands are visibly dirty they must be washed with soap and under running water. If hands are not visibly dirty they may be cleaned using an alcohol-based hand rub/sanitizer but even then it is better to wash them with soap and under running water $[15,16]$. Around $56 \%$ of respondents clean their hands with soap and under running water, around $30 \%$ use a hand sanitizer and about $11 \%$ use soap and water but not the running water for it [Table 4]. 
Frequent hand washing has been recommended as one of the most imperative steps for protection against COVID-19 as said above, but guidelines do not mention or recommend the frequency of handwashing because it is largely subjective and depends on various factors including work profile. For example a person sitting in his/her neat \& clean office for most of the time of the day may require less frequent hand sanitization than a person serving in a health care facility. The responses received for QP4 showed wide variability in the frequency of handwashing with ' $5-10$ times a day' being the most common followed by 'more than 10 times, ' $3-5$ times', and ' $1-2$ times' a day respectively [Table 4].

SARS-CoV-2 is contained in the respiratory droplets of the infected person which may pour onto the other surfaces making them also a potential source of infection. Therefore the right practice of coughing and /or sneezing becomes very important for community transmission of the virus. It is recommended to cough or sneeze into the inner side of the elbow and not into the palms [28] because hands are the parts of the body that are touched to the external objects maximally. Nearly Sixty-four percent of the participants practice it into the inner side of the elbow whereas one fourth do it into their palms. Around $6.5 \%$ try to stop the reflex and $4.2 \%$ practice it into open (QP5) [Table 4].

Mode of greeting may also play an important role in the human-to-human transmission of the disease. For example, hands or other parts of the body of a person could become potentially infected with the pathogen after being touched to the nose or after laying of pathogens following an act of sneezing/coughing, so the infection may spread from a person to another by handshaking or hugging, the two common modes of greeting, unknowingly. 'Namaskar' does not require touching to or being touched by the person in front therefore may seem to relatively be safer [24]. Surprisingly more than threefourths of the respondents greet through 'Namaskar', around five percent through a handshake, $~ 17 \%$ by other modes and none through hugging, which may indicate a high-level awareness among people about human-to-human transmission through 'touch' (QP6) [Table 4].

From the discussion above it seems to become apparent 'how important to keep oneself protected from potential sources of infection, is?', because SARS-CoV-2 has been seen to be spread by asymptomatic infected persons as well. Keeping in mind its higher/easy communicability it is recommended to reduce outdoor activities as low as possible. The next question (P7) was formulated to know the awareness of people and practice followed by them in this context. And it is soothing to know that more than $95 \%$ of the participants have understood the fact and have minimized their outdoor activities [Table 4].

As mentioned earlier, the SARS-CoV-2 is released in respiratory droplets of an infected person while coughing and/or sneezing but it is difficult for such a large size (outer diameter 50-200 nm) viral particle to travel beyond a distance of around $2-4$ feet $[11,29]$. Therefore it is recommended to keep a physical distance of at least one meter while communicating with others especially from those suffering from flulike symptoms [19]. This 'social distancing' could be one of the most effective measures to detain its community transmission. Around $92 \%$ of the respondents showed their awareness about this practice to answer QP8 [Table 4]. 
Because of the inhalational route being the key to the transmission of COVID-19, the use of a medical mask has been promoted a lot by the media. However, there is no convincing evidence showing the benefit of using a medical mask by the general public, and also governing bodies do not recommend its routine use by the general public as mentioned earlier. It was tried to know the extent of the use of a medical mask by the general public in India in QP9. More than two-thirds of the respondents have used it since the origin of the outbreak of COVID-19 [Table 4] which may indicate an impact of the promotion by the media.

Our study reveals a fair correlation between knowledge and attitude and between knowledge and practice and a good correlation between attitude and practices followed towards COVID-19. Moreover, the correlations among all the three KAP parameters were statistically significant [Table 6]. Thus the association among these three parameters indicates, attitude is affected to a significant extent by the presence of knowledge and similarly the practice followed (which directly relates to community spread of SARS-CoV-2) in a population is, in turn, affected significantly by its attitude. Therefore the presence of correct knowledge, positive attitude, and appropriate practices towards COVID-19 among the general public help control its spread in human society.

\section{Conclusion And Recommendations}

In conclusion, the presence of adequate knowledge, positivity in attitude and dominance of appropriate practices among the general public could be one of the contributing factors to a relatively lower rate of rising of COVID-19 cases in India. But on the other hand, some lack of knowledge, negativity in attitude, and inappropriate practices followed by a section of the public may impart in a continuous rise in the number of COVID-19 cases.

The study used a validated and well balanced questionnaire relevant to general public to cover all the three aspects viz knowledge, attitude and practice appropriately. Awareness among the general public with regard to transmission of COVID-19 seems to be more important than putting obligation on it to follow instructions, and this study tends to assess the same. Data may be helpful to make regulatory decisions and/or taking steps to create awareness more efficiently among the public.

Though the responses were received from various states and/or union-territories of India, the study enrolled the participants through online mode only. For this reason, people who do not have access to the internet or e-mail and who do not understand the written English language (which may be related to their socioeconomic status also) could not participate, so the study results may not be generalizable to the whole of the population of the country. Therefore further studies are desirable covering a larger portion of the population more efficiently representing the nation as a whole.

Though it is difficult to comment on the proportion of the population that should have the correct knowledge, positive attitude and follow appropriate practices to conquer the present mishap, it is always better it to be had by the maximum, therefore it is recommended to make the awareness material for the public, issued by the administration, more easily accessible for its beneficiary. 


\section{Abbreviations}

2019-nCoV: novel Coronavirus-2019; COVID-19: Coronavirus disease 2019; KAP: knowledge, attitude and practice; MERS: Middle East respiratory syndrome; $\mathrm{R}_{0}$ : basic reproduction number; SARS: Severe acure respiratory syndrome; SARS-CoV-2: Severe acute respiratory syndrome Coronavirus-2; WHO: World Health Organization.

\section{Declarations}

Ethics approval and consent to participate: Ethical requirement was fulfilled as per the Declaration of Helsinki obtaining an online informed consent from all the participants enrolled without coming into their physical contact at the time of ongoing COVID-19 pandemic.

Consent for publication: Participants were informed of future publication of the data without disclosing their personal information.

Availability of data and material: The datasets used and/or analysed during the current study are available from the corresponding author on reasonable request.

Competing interests: The authors declare that they have no competing interests.

Funding: Study did not receive any funding from any funding body.

\section{Authors' contributions:}

VM: Conceptualization, designing questionnaire, data collection, data compilation, manuscript preparation

PP: Approving questionnaire, data collection, manuscript approval

DKJ: Approving questionnaire, data collection, manuscript approval

VS: Dataanalysis, manuscript preparation, manuscript approval

Acknowledgements: Not applicable

\section{References}

1. World Health Organization. Origin of SARS-CoV-2 (26. March 2020). Available at https://www.who.int/health-topics/coronavirus/who-recommendations-to-reduce-risk-oftransmission-of-emerging-pathogens-from-animals-to-humans-in-live-animal-markets. Accessed April $25,2020$.

2. World Health Organization. Naming the coronavirus disease (COVID-19) and the virus that causes it. Available at https://www.who.int/emergencies/diseases/novel-coronavirus-2019/technical- 
guidance/naming-the-coronavirus-disease-(covid-2019)-and-the-virus-that-causes-it. Accessed April 19, 2020.

3. Ravelo JL, Jerving S. COVID-19- a timeline of the coronavirus outbreak. Available at https://www.devex.com/news/covid-19-a-timeline-of-the-coronavirus-outbreak-96396. Accessed April 19, 2020.

4. World Health Organization. Coronavirus (COVID-19)events as they happen. Available at who.int/emergencies/diseases/novel-coronavirus-2019/events-as-they-happen. Accessed April 19, 2020.

5. World Health Organization. WHO Director-General's opening remarks at the media briefing on COVID19- 11 March 2020. Available at https://www.who.int/dg/speeches/detail/who-director-general-sopening-remarks-at-the-media-briefing-on-covid-19--11-march-2020. Accessed April 19, 2020.

6. Centers for Disease Control and Prevention

Flu)

Centers for Disease Control and Prevention. Influenza. (Flu): 2009 H1N1 Pandemic (H1N1pdm09 virus). Available at https://www.cdc.gov/flu/pandemic-resources/2009-h1n1-pandemic.html. Accessed April 19, 2020.

7. World Health Organization. Coronavirus disease (COVID-19) Pandemic: Coronavirus disease (COVID19) outbreak situation. Available at https://www.who.int/emergencies/diseases/novel-coronavirus2019. Accessed April 29, 2020.

8. Park M, Thwaites RS, Openshaw PJM. COVID-19: Lessons from SARS and MERS. Eur J Immunol. 2020;50:308-16.

9. Ye F, Xu S, Rong Z, et al. Delivery of infection from asymptomatic carriers of COVID-19 in a familial cluster. Int J Infect Dis. 2020. (doi: https://doi.org/10.1016/j.jij.2020.03.042).

10. World Health Organization. Coronavirus disease 2019 (COVID-19): Situation Report-73. Available at https://www.who.int/docs/default-source/coronaviruse/situation-reports/20200402-sitrep-73-covid19.pdf?sfvrsn=5ae25bc7_2. Accessed April 19, 2020.

11. World Health Organization. Modes of transmission of virus causing COVID-19: implications for IPC precaution recommendations. Available at https://www.who.int/newsroom/commentaries/detail/modes-of-transmission-of-virus-causing-covid-19-implications-for-ipcprecaution-recommendations. Accessed April 24, 2020.

12. Luo C, Yao L, Zhang L, et al. Possible Transmission of Severe Acute Respiratory Syndrome Coronavirus 2 (SARS-CoV-2) in a Public Bath Center in Huai'an, Jiangsu Province, China. JAMA Network Open. 2020;3:e204583. (doi: 10.1001/jamanetworkopen.2020.4583).

13. van-Doremalen N, Bushmaker T, Morris DH, et al. Aerosol and surface stability of SARS-CoV-2 as compared with SARS-CoV-1. N Eng J Med. 2020;382:16. (doi: 10.1056/NEJMc2004973).

14. Government of India. Ministry of Health \& Family Welfare, Directorate General of Health Services (EMR Division). Guidelines for home quarantine. Available at https://www.mohfw.gov.in/pdf/Guidelinesforhomequarantine.pdf. Accessed April 24, 2020. 
15. Ministry of Health \& Family Welfare, Directorate General of Health Services (Emergency Medical Relief). Novel Coronavirus Disease (COVID-19): Guidelines on use of masks by public. Available at https://www.mohfw.gov.in/pdf/Useofmaskbypublic.pdf. Accessed March 31, 2020.

16. World Health Organization. Advice on the use of masks in the context of COVID-19 (Interim guidance). Available at https://apps.who.int/iris/rest/bitstreams/1274280/retrieve. Accessed April $24,2020$.

17. UNICEF. Key messages and actions for COVID-19 prevention and control in schools. (March 2020). Available at https://www.who.int/docs/default-source/coronaviruse/key-messages-and-actions-forcovid-19-prevention-and-control-in-schools-march-2020.pdf?sfvrsn=baf81d52_4. Accessed April 24, 2020.

18. Government of India, Ministry of Health \& Family Welfare. Directorate General of Health Services (EMR Division). COVID-19: Guidelines on dead body management. Available at https://www.mohfw.gov.in/pdf/1584423700568_COVID19GuidelinesonDeadbodymanagement.pdf. Accessed March 21, 2020.

19. Government of India. Ministry of Health \& Family Welfare. Advisory on social distancing measure in view of spread of COVID-19 disease. Available at https://www.mohfw.gov.in/pdf/SocialDistancingAdvisorybyMOHFW.pdf. Accessed March 23, 2020.

20. World Health Organization. "Immunity passports" in the context of COVID-19 (Scientific brief). Available at https://www.who.int/news-room/commentaries/detail/immunity-passports-in-thecontext-of-covid-19. Accessed April 25, 2020.

21. Infant and Young Child Feeding: Model Chapter for Textbooks for Medical Students and Allied Health Professionals. Geneva: World Health Organization; 2009. ANNEX 1, Acceptable medical reasons for use of breast-milk substitutes. Available at https://www.ncbi.nlm.nih.gov/books/NBK148964/. Accessed April 25, 2020.

22. World Health Organization. Q\&A on COVID-19, pregnancy, childbirth and breastfeeding. Available at https://www.who.int/news-room/q-a-detail/q-a-on-covid-19-pregnancy-childbirth-and-breastfeeding. Accessed April 25, 2020.

23. Preeti Sudha VB, Ganesan S, Pazhani GP, Ramamurthy T, Nair GB, Venkatasubramanian P. Storing drinking-water in copper pots kills contaminating diarrhoeagenic bacteria. J Health Popul Nutr. 2012;30:17-21.

24. Bhattacharya S, Singh A. Namastey!! Greet the Indian way: Reduce the chance of infections in the hospitals and community. CHRISMED J Health Res. 2019;6:77-8.

25. Pellerin J, Edmond MB. Infections associated with religious rituals. Int J Infect Dis. 2013;17:e945-8.

26. Araujo MB, Naimi B. Spread of SARS-CoV-2 Coronavirus likely constrained by climate. BMJ. 2020. Available at https://www.medrxiv.org/content/10.1101/2020.03.12.20034728v1.full.pdf. Accessed April 25, 2020.

27. Government pf Karnataka, National Health Mission. Detail question and answers on COVID-19 for public. Available at https://www.mohfw.gov.in/pdf/FAQ.pdf. Accessed April 25, 2020. 
28. Government of India. Ministry of Personnel, Public Grievances and Pension (Department of Personnel and Training). Preventive measures to be taken to contain the spread of Novel Coronavirus (COVID-19). Available at https://www.mohfw.gov.in/pdf/PreventivemeasuresDOPT.pdf. Accessed March 23, 2020.

29. Chen N, Zhou M, Dong X, et al. Epidemiological and clinical characteristics of 99 cases of 2019 novel coronavirus pneumonia in Wuhan, China: a descriptive study. Lancet. 2020;395:507-13.

\section{Tables}

Table 1: Demographic characteristics of study participants $(\mathrm{N}=229)$

\begin{tabular}{|c|c|c|}
\hline Characteristics & $\mathrm{n}$ & $\%$ \\
\hline \multicolumn{3}{|l|}{ QD1. Age (in years) } \\
\hline $18-<45$ & 198 & 86.5 \\
\hline $45-<60$ & 21 & 9.2 \\
\hline 60 or above & 10 & 4.4 \\
\hline \multicolumn{3}{|l|}{ QD2. Gender } \\
\hline Male & 143 & 62.5 \\
\hline Female & 86 & 37.6 \\
\hline Others & 0 & 0.0 \\
\hline \multicolumn{3}{|c|}{ QD3. State/Union territory of your current residence } \\
\hline Rajasthan & 52 & 22.7 \\
\hline Haryana & 30 & 13.1 \\
\hline Delhi & 26 & 11.4 \\
\hline Karnataka & 24 & 10.5 \\
\hline Uttar Pradesh & 22 & 9.6 \\
\hline Bihar & 19 & 8.3 \\
\hline Jharkhand & 14 & 6.1 \\
\hline Himachal Pradesh & 9 & 3.9 \\
\hline Maharashtra & 8 & 3.5 \\
\hline Uttarakhand & 8 & 3.5 \\
\hline Others & 17 & 7.4 \\
\hline \multicolumn{3}{|c|}{ QD4. Are you suffering from or did you suffer from common cold symptoms within the past 14 days? } \\
\hline Yes & 33 & 14.5 \\
\hline No & 196 & 85.5 \\
\hline \multicolumn{3}{|c|}{ QD5. Have you ever been tested positive for COVID-19? } \\
\hline Yes & 0 & 0 \\
\hline No & 229 & 100 \\
\hline
\end{tabular}

Table 2: Knowledge of general public regarding COVID-19 
Talking closely to a patient

Sharing the same bed with the patient

Eating together with the patient in the same utensil

Video calling with patient

\begin{tabular}{|l|l|l|}
\hline 0 & 64 & 28.9 \\
\hline 0 & 9 & 4.1 \\
\hline 0 & 19 & 8.6 \\
\hline 1 & 129 & 58.4 \\
\hline
\end{tabular}

QK2. Which liquid solution has been recommended to disinfect/clean the surfaces which have come in contact with a COVID-19 patient?

Warm water

$1 \%$ sodium hypochlorite

25\% alcohol

\begin{tabular}{|l|l|l|}
\hline 0 & 26 & 11.7 \\
\hline 1 & 70 & 31.4 \\
\hline 0 & 126 & 56.5 \\
\hline 0 & 1 & 0.5 \\
\hline
\end{tabular}

Boiled and cooled water

QK3. Which one of the following sentences is the most appropriate in your knowledge regarding the use of a mask for prevention of transmission of SARS-CoV-2:

An asymptomatic person without any contact history need not wear a mask routinely

A person without any contact history, having common cold symptoms need not wear a mask

One mask remains effective at least for 24 hours

Mask can be reused after washing it with hot water

\begin{tabular}{|l|l|l|l|}
\hline 1 & 71 & 32.1 \\
\hline 0 & 26 & 11.8 \\
& 0 & 72 & 32.6 \\
\hline 0 & 52 & 23.5 \\
\hline
\end{tabular}

QK4. Have you ever read or been told by some trained person about the correct technique of wearing and removing the mask?

\begin{tabular}{|l|l|l|l|}
\hline Yes & 1 & 110 & 48.9 \\
\hline No & 0 & 115 & 51.1 \\
\hline
\end{tabular}

QK5. Which one of the following sentences is most appropriate in your knowledge for prevention of transmission of SARS-CoV-2:

Frequent hand washing is recommended only for those who give care to COVID-19 patient

Wearing a mask is recommended only for those suffering from COVID-19 and persons at high risk to develop it

Separation is only for confirmed cases of COVID-19

Fever, cough, and difficulty in breathing develop only in those suffering from COVID-19

\begin{tabular}{|l|l|l|l|}
\hline 0 & 25 & 11.3 \\
\hline 1 & 68 & 30.7 \\
\hline 0 & 68 & 30.7 \\
\hline 0 & 61 & 27.5 \\
\hline
\end{tabular}

QK6. Which one of the following measures is NOT recommended to prevent transmission of SARS-CoV-2 in your knowledge?

Frequent handwashing with soap and water

Using single tissue paper for coughing/sneezing for a day without sharing it with others

Making children aware of the disease and the precautions to be taken

Avoiding visit in public places as far as possible

\begin{tabular}{|l|l|l|}
\hline 0 & 14 & 6.4 \\
\hline 1 & 152 & 69.1 \\
\hline 0 & 32 & 14.6 \\
\hline 0 & 22 & 10.0 \\
\hline
\end{tabular}

QK7. Suppose you had come in contact with a patient suffering from COVID-19 unknowingly in the past 14 days and now you are experiencing fever and difficulty in breathing. Which one of the following steps should you NOT follow?

Inform healthcare facility

You will call and gather your relatives around you

You will separate yourself from other close contacts

You will make others aware/informed about your illness

\begin{tabular}{|l|l|l|}
\hline 0 & 26 & 11.8 \\
\hline 1 & 160 & 72.4 \\
\hline 0 & 23 & 10.4 \\
\hline 0 & 12 & 5.4 \\
\hline
\end{tabular}

QK8. Which one of the following steps you should follow to care for one of your relatives having a history of close contact with a COVID-19 patient?

Keep your relative in a separate room keeping all the windows and ventilators closed to prevent the spread of the virus

Shake thoroughly his/her linen/bedsheet on a daily basis to maintain hygiene

Allow only one visitor at a time to meet the person and not all simultaneously

You will wash your hands with soap and water even after using disposable gloves while

\begin{tabular}{|l|l|l|}
\hline & 116 & 53.2 \\
\hline 0 & 5 & 2.3 \\
\hline 0 & 18 & 8.3 \\
\hline 1 & 79 & 36.2
\end{tabular}


QK9. Choose one of the most appropriate from the following practices in your knowledge, with regard to the body of a patient, died of COVID-19:

Bathing of and hugging to the body is safe and may be allowed to respect the emotions of relatives

Funeral of the dead body should not be allowed

The funeral may be allowed but ash cannot be collected

The funeral may be allowed and ash collection as a ritual may be considered safe

\begin{tabular}{|l|l|l|l|}
\hline 0 & 11 & 5.1 \\
& 0 & 86 & 40.0 \\
\hline 0 & 54 & 25.1 \\
\hline 1 & 64 & 29.8 \\
\hline
\end{tabular}

Table 3: Attitude of the general public towards COVID-19 


\section{Questions with scoring}

QA1. Do you think steps being taken by the Government of India are worth and will be helpful to limit the spread of this disease in India?

\begin{tabular}{|l|l|l|l|}
\hline Yes & 1 & 162 & 74.7 \\
\hline No & -1 & 21 & 9.7 \\
\hline Cannot comment & 0 & 34 & 15.7 \\
\hline
\end{tabular}

QA2. Do you think keeping a physical distance from a COVID-19 patient or from a person with a history of close contact makes him/her feel embarrassed/ inferior?

\begin{tabular}{|l|l|l|l}
\hline Yes & -1 & 71 & 32.6 \\
\hline No & 1 & 110 & 50.5 \\
\hline Cannot comment & 0 & 37 & 16.9
\end{tabular}

QA3. Do you think all the family members should give care to a COVID-19 patient, one-by-one, to reduce the risk of infection to a single family member and to make the patient feel emotionally better?

\begin{tabular}{|l|l|l|l}
\hline Yes & -1 & 59 & 27.2 \\
\hline No & 1 & 142 & 65.4 \\
\hline Cannot comment & 0 & 16 & 7.4 \\
\hline
\end{tabular}

QA4. Do you think taking precautions at a personal level will benefit human society to combat with COVID-19?

\begin{tabular}{|l|l|l|l}
\hline Yes & 1 & 194 & 89.4 \\
\hline No & -1 & 13 & 5.9 \\
\hline Cannot comment & 0 & 10 & 4.6
\end{tabular}

QA5. Do you think that you cannot suffer from COVID-19 as your immunity is strong enough therefore you do not require taking precautionary measures?

\begin{tabular}{|l|l|l|l}
\hline Yes & -1 & 32 & 14.7 \\
\hline No & 1 & 186 & 85.3
\end{tabular}

\section{Questions without scoring}

QA6. Should a nursing mother suffering from COVID-19, continue to breastfeed her newborn baby, in your opinion?

\begin{tabular}{|l|l|l|l|}
\hline Yes & NA & 32 & 14.7 \\
\hline No & NA & 186 & 85.3 \\
\hline
\end{tabular}

QA7. Do you think ancient practices followed in Indian culture are protective against communicable diseases like COVID-19, by and large?

\begin{tabular}{|l|l|l|l|}
\hline Yes & NA & 92 & 42.4 \\
\hline No & NA & 64 & 29.5 \\
\hline Cannot comment & NA & 61 & 28.1 \\
\hline
\end{tabular}

QA8. Do you see non-vegetarian food habit in any manner, as a risk factor for the origin and/or spread of SARS-CoV-2?

\begin{tabular}{|l|l|l|l|}
\hline Yes & NA & 99 & 45.4 \\
\hline No & NA & 57 & 26.2 \\
\hline Can't say & NA & 62 & 28.4 \\
\hline QA9. In your opinion, for how long the problem of SARS-CoV-2 infection will remain prevalent in India? \\
\hline For less than a month & NA & 25 & 11.5 \\
\hline For the next 1-3 months & NA & 96 & 44.0 \\
\hline For the next 3-6 months & NA & 64 & 29.36 \\
\hline For more than 6 months & NA & 33 & 15.14 \\
\hline
\end{tabular}


Table 4: Practices followed by the general public towards COVID-19 


\section{Questions with scoring}

QP1. Suppose you had come in contact with an asymptomatic person within the past 10 days. Now that person has been found positive for SARS-CoV-2 infection. Which one of the following steps will you practice?

\begin{tabular}{|c|c|c|c|}
\hline You will rush to the hospital & 0 & 62 & 28.4 \\
\hline You will call a doctor at your home & 0 & 18 & 8.3 \\
\hline You will inform about the positive case in your neighborhood going their home & 0 & 14 & 6.4 \\
\hline You will quarantine yourself & 1 & 124 & 56.9 \\
\hline
\end{tabular}

QP2. Suppose you came in close contact with COVID-19 patient unknowingly yesterday. Choose the most appropriate step that you will practice.

You will restrict your activities to your household and household members only

You will take the blessings of elderly people at home by touching their feet for your better health

You will restrict your visit only to important wedding's and not others

You will wear mask all/most of the time

\begin{tabular}{|l|l|l|}
\hline 0 & 95 & 44.6 \\
\hline 0 & 1 & 0.5 \\
\hline 0 & 2 & 0.9 \\
\hline 1 & 115 & 53.9 \\
\hline
\end{tabular}

QP3. How do you practice your hand cleanliness mostly?

Washing with soap (solid or liquid) and water using a jug/glass

Cleaning with hand rub/sanitizer available in market

Washing with soap (solid or liquid) under running water

Washing with plain tap water/Other

QP4. How many times in a day do you wash/clean your hands?

\begin{tabular}{|c|c|c|c|}
\hline 1-2 times & 0.25 & 19 & 8.8 \\
\hline $3-5$ times & 0.5 & 63 & 29.3 \\
\hline $5-10$ times & 0.75 & 76 & 35.4 \\
\hline More than 10 times & 1 & 57 & 26.5 \\
\hline
\end{tabular}

QP5. How do you cough or sneeze whenever you have to do so?

Into palms of your hands

Into the inner side of your elbow

Try to stop coughing/ sneezing

Cough/ sneeze in open, as viruses can't survive outside the body

QP6. How do you greet your colleagues?

By Handshake

By Namaskar

By Hugging

By other modes

\begin{tabular}{|l|l|l|}
\hline 0.5 & 24 & 11.5 \\
\hline 0.75 & 62 & 29.8 \\
\hline 1 & 116 & 55.8 \\
\hline 0.25 & 6 & 2.9 \\
\hline
\end{tabular}

QP7. Are you regularly visiting an outdoor place of your choice like a public gym, public temple, a place for leisure activity with your friends, or any other place, thinking that it keeps your mind healthy and boosts your immunity and thus keeps you protected against SARS-CoV-2 infection?

\begin{tabular}{|l|l|l|l|}
\hline Yes & 0 & 10 & 4.6 \\
\hline No & 1 & 207 & 95.4 \\
\hline
\end{tabular}

QP8. Do you keep a physical distance of at least one meter while communicating with others (especially those having flu-like symptoms) physically?

\begin{tabular}{|l|l|l|l|}
\hline Yes & 1 & 200 & 92.2 \\
\hline No & 0 & 17 & 7.8 \\
\hline
\end{tabular}

\section{Questions without scoring}

QP9. Have you ever used any medical mask (two-ply, three-ply, or N95) for your personal protection against COVID-19 after the occurrence of its outbreak in China?

Yes

Page 22/24

\begin{tabular}{|l|l|l|}
\hline NA & 146 & 67.6 \\
\hline
\end{tabular}


Table 5: Comparisons of Demographic Characteristics with respect to KAP Scores

\begin{tabular}{|c|c|c|c|c|c|c|c|}
\hline \multirow[t]{2}{*}{ haracteristics } & \multirow[t]{2}{*}{ n (\%) } & \multicolumn{2}{|c|}{ Knowledge parameter } & \multicolumn{2}{|c|}{ Attitude parameter } & \multicolumn{2}{|c|}{ Practice parameter } \\
\hline & & $\begin{array}{l}\text { Score (Mean } \pm \\
\text { SD) / } \\
\text { Median (IQR) }\end{array}$ & \multirow[t]{2}{*}{$\begin{array}{c}\mathrm{p}- \\
\text { value }\end{array}$} & $\begin{array}{c}\text { Score (Mean } \pm \\
\text { SD) / } \\
\text { Median (IQR) }\end{array}$ & \multirow[t]{2}{*}{$\begin{array}{c}\mathrm{p}- \\
\text { value }\end{array}$} & $\begin{array}{c}\text { Score (Mean } \pm \\
\text { SD)/ } \\
\text { Median (IQR) }\end{array}$ & \multirow[t]{2}{*}{$\begin{array}{c}\mathrm{p}- \\
\text { value }\end{array}$} \\
\hline otal & $\begin{array}{l}229 \\
(100)\end{array}$ & $\begin{array}{l}.9(1.9) / 4.0 \\
(3.0)\end{array}$ & & $\begin{array}{l}2.6(2.1) / 3.0 \\
(4.0)\end{array}$ & & $\begin{array}{l}5.9(1.9) / 6.3 \\
(1.8)\end{array}$ & \\
\hline \multicolumn{8}{|l|}{ ge (in years) } \\
\hline $8-45$ & $\begin{array}{l}198 \\
(86.5)\end{array}$ & $\begin{array}{l}4.0(1.9) / 4.0 \\
(3.0)\end{array}$ & \multirow[t]{3}{*}{0.20} & $\begin{array}{l}2.7(2.1) / 3.0 \\
(4.0)\end{array}$ & \multirow[t]{3}{*}{0.19} & $\begin{array}{l}5.9(2.0) / 6.3 \\
(2.0)\end{array}$ & \multirow[t]{3}{*}{0.81} \\
\hline $5-<60$ & $21(9.2)$ & $\begin{array}{l}3.7(1.6) / 4.0 \\
(2.0)\end{array}$ & & $\begin{array}{l}2.1(2.4) / 2.0 \\
(5.0)\end{array}$ & & $\begin{array}{l}6.1(1.5) / 6.5 \\
(1.3)\end{array}$ & \\
\hline 0 or above & $10(4.5)$ & $\begin{array}{l}3.0(1.9) / 2.5 \\
(2.0)\end{array}$ & & $\begin{array}{l}2.0(2.5) /-3.0 \\
(2.0)\end{array}$ & & $\begin{array}{l}5.9(1.2) / 6.3 \\
(1.0)\end{array}$ & \\
\hline \multicolumn{8}{|l|}{ iender } \\
\hline Iale & $\begin{array}{l}143 \\
(62.4)\end{array}$ & $\begin{array}{l}3.9(2.0) / 4.0 \\
(3.0)\end{array}$ & \multirow[t]{2}{*}{0.91} & $\begin{array}{l}2.5(2.1) / 3.0 \\
(4.0)\end{array}$ & \multirow[t]{2}{*}{0.38} & $\begin{array}{l}5.8(2.2) / 6.3 \\
(2.0)\end{array}$ & \multirow[t]{2}{*}{0.25} \\
\hline emale & $\begin{array}{l}86 \\
(37.6)\end{array}$ & $\begin{array}{l}3.9(1.9) / 4.0 \\
(2.0)\end{array}$ & & $\begin{array}{l}2.7(2.2) / 3.0 \\
(4.0)\end{array}$ & & $\begin{array}{l}6.1(1.4) / 6.4 \\
(1.8)\end{array}$ & \\
\hline
\end{tabular}

Table 6: Correlation among knowledge, attitude and practice scores

\begin{tabular}{|l|l|l|}
\hline Variable & Correlation coefficient $(\mathrm{r})^{*}$ & p-value \\
\hline Knowledge-Attitude & 0.314 & $<0.001$ \\
\hline Knowledge-Practice & 0.275 & $<0.001$ \\
\hline Attitude-Practice & 0.522 & $<0.001$ \\
\hline
\end{tabular}

${ }^{*}<0.25$ (weak correlation); $0.25-<0.50$ (fair correlation); $0.50-<0.75$ (good correlation) and $\geq 0.75$ (excellent correlation)

$\mathrm{p}<0.05$ : statistically significant

\section{Figures}




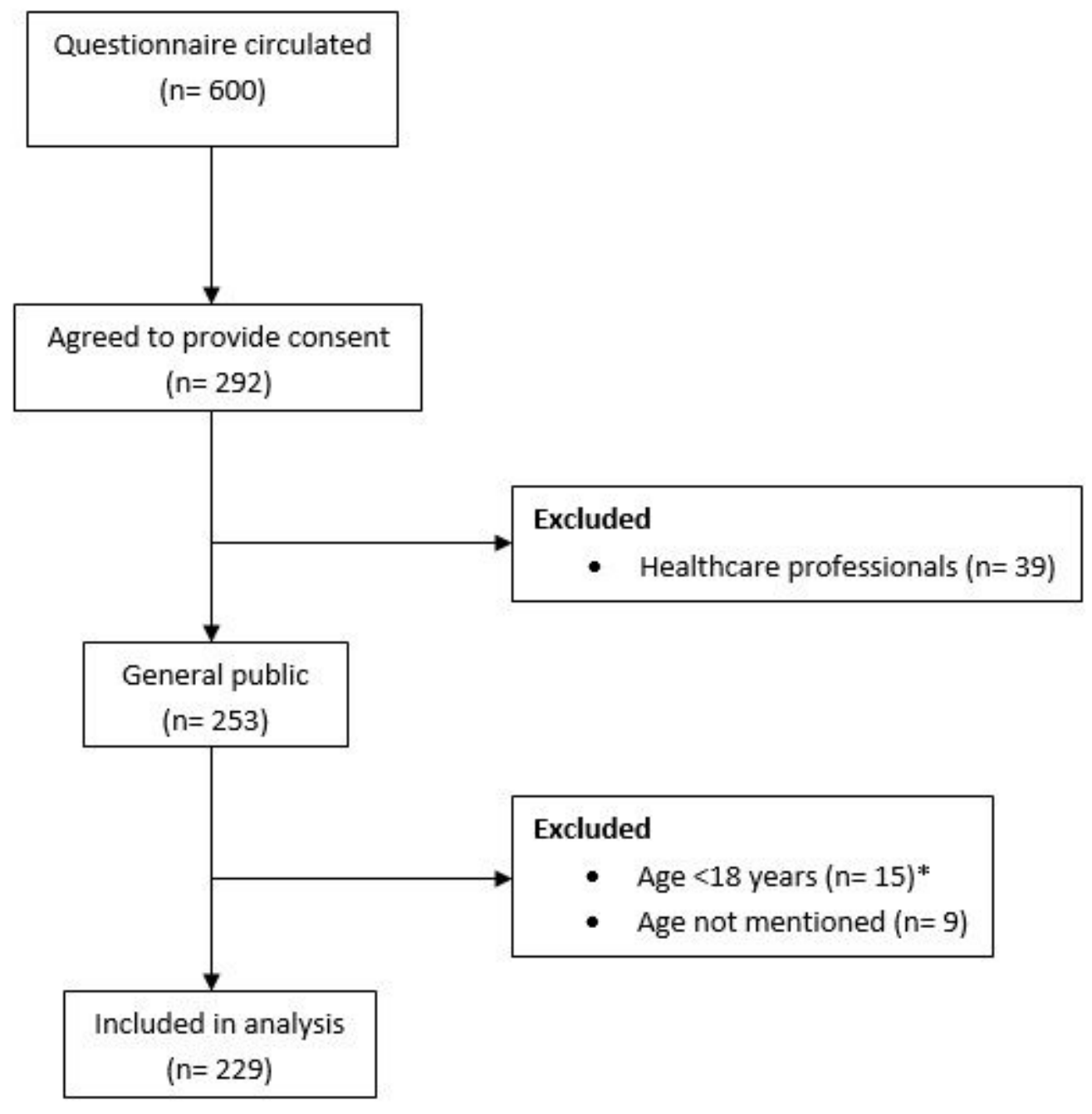

Figure 1

Enrollment of participants *Adults are defined as individuals with the age $>18$ years (in India), and are eligible to provide informed consent.

\section{Supplementary Files}

This is a list of supplementary files associated with this preprint. Click to download.

- Questionnaire.docx 